\title{
Operative Time is an Independent Risk Factor for Complications in Adult Spinal Deformity Surgery
}

\author{
Robert E Eastlack* \\ Department of Orthopedic Surgery, USA
}

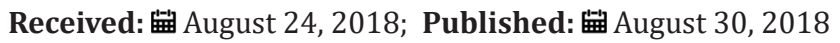

*Corresponding author: Robert E Eastlack, Department of Orthopedic Surgery, San Diego Spine Foundation, San Diego, California, USA

Abbreviations: ASD: Adult Spinal Deformity; EBL: Estimated Blood Loss; ASA: American Society of Anesthesiologists; IRB: Institutional Review board

\section{Introduction}

The prevalence of Adult Spinal Deformity (ASD) is increasing as the demographic of Western societies shift towards a more elderly population [1]. As the spine ages, multiple degenerative changes occur within this complex support structure. Adult spinal deformity is often the result of progressive degenerative changes. A growing financial burden on the healthcare system exists with the rising prevalence of ASD and a commensurate increased rate of surgical treatment for the condition. Surgical treatment for ASD is reserved for patients whose pain and disability have not responded to nonoperative care and often requires extensive reconstruction [2-5]. While numerous studies have demonstrated the clinical benefits of surgical treatment for ASD, these procedures are not without significant risks and cost [6-8].

Reported rates of complications for ASD have ranged from under $10 \%$ up to $80 \%[7,9-11]$. These complication rates are significantly higher than rates associated with surgical treatment of non-deformity degenerative conditions. Identifying patient, surgical, and perioperative risk factors are essential for the surgeons and patient to evaluate the risk-benefit ratio of ASD surgery. Previous studies have identified factors such as increasing age, Estimated Blood Loss (EBL), comorbidities, preoperative deformity, and American Society of Anesthesiologists (ASA) grade that are correlated with increase risk of complications with ASD surgery. The duration of surgery has not been well studied as a risk factor for ASD surgery [11-16]. The purpose of this study was to quantify the risk of complications based on the duration of ASD surgery.

\section{Methods}

\section{Study Design and Inclusion Criteria}

This is a multi-center retrospective review of a prospectively collected database of ASD patients who underwent corrective surgery between 2008-2014. Institutional Review board (IRB) approval was obtained at all 13 participating sites. Inclusion criteria were age $\geq 18$ years and at least one of the following: major coronal Cobb angle $\geq 20^{\circ}$, sagittal vertical axis $\geq 5 \mathrm{~cm}$, pelvic tilt $\geq$ $25^{\circ}$, and/or lumbar scoliosis $\geq 20^{\circ}$, and minimum 2 year follow-up. Staged surgery as well as patients with spinal deformity resulting from neuromuscular conditions, tumor, or infection were excluded.

\section{Data Collection and Analysis}

Demographic information was collected at baseline. Healthrelated quality-of-life outcomes, including the Oswestry Disability Index (ODI), back and leg pain numerical rating scale, and Scoliosis Research Society Patient Questionnaire (SRS-22r) were collected at all time points (baseline, six weeks, one year, and two years). Patient satisfaction was analyzed using the SRS-22r patient satisfaction domain. Radiographic parameters included sagittal vertical axis (SVA), pelvic tilt (PT), Pelvic Incidence (PI), Lumbar Lordosis (LL), and pelvic incidence minus lumbar lordosis mismatch (PI-LL). Total levels instrumented, operative time (minutes between incision and closing), length of hospital stay (days), and presence of threecolumn osteotomies were also assessed.

Patient surgical date, complications, reoperation dates, and health-related quality-of-life outcomes were collected. Reoperation 
was defined as an unplanned return to the operating room resulting from the primary surgical procedure and was related to surgical technique and factors that could impact outcomes. Complication categories included reoperation, major, minor, intraoperative, predischarge, post-discharge, cardiopulmonary, implant, infection, neurologic, operative, radiographic, renal, vascular, and wound related. Intraoperative complications were those recorded in the operating room. Postoperative complications were monitored for two years postoperatively.

\section{Statistical Analysis}

Univariate logistic regression tested significant association between operative (OR) time, as a continuous variable and all complication categories. Multivariate logistic regressions were applied to all complication categories that had a significant univariate association with OR time. Covariates available in the database that were assessed included baseline demographic such as age, BMI, past surgical history and Charlson comorbidity score, as well as surgical techniques including 3 column osteotomies, total number of osteotomies, approach (anterior, posterior anterior-posterior), total levels instrumented and institution. Associations between each covariate and complication was tested in a univariate model and if found significant was included in a secondary model with OR time. Covariates were excluded from the final multivariate model if it had a $p>0.2$ and did not confound the relationship between OR time and complication by more than $20 \%$. Final multivariate analysis controlled for Charlson score, total instrumented levels, and institution. Additional analyses included creating binary variables of OR time by the hour $(<3$ vs $3 \leq,<4$ vs $4 \leq$, etc), as the variable of interest in further multivariate logistic regression models.

\section{Result}

A total of 349 patients met the inclusion criteria. The demographics and surgical parameters of these patients were as follows (Table 1): Mean age of 58 years and mean BMI of 27.2 $\mathrm{kg} / \mathrm{m} 2$, the mean number of levels instrumented was 11.1 (SD = 4.2, range 1-19), mean total OR time of 392 minutes $(\mathrm{SD}=125.7$, range 111-802), mean EBL of $1930 \mathrm{~mL}(\mathrm{SD}=1607$, range 5012200 ), and mean length of stay of 7.4 days ( $S D=4.2$, range 3-49). Mean preoperative radiographic and outcome parameters were as follows Table 1: preoperative back pain VAS $7.1(\mathrm{SD}=2.3$, range $0-10$ ), preoperative leg pain 4.5 ( $S D=3.4$, range $0-10$ ), preoperative ODI 42.0 (SD = 18.9, range 0-92), max cobb angle 42.2 degrees (SD = 20.8, range 6.3-123.7), PT 23.3 (SD = 11.2, range -8.4-67.8), PI $54.8(\mathrm{SD}=12.9$, range 11.9-100), LL $41.0(\mathrm{SD}=21.6$, range 30.788.9), PI-LL 13.7 (SD = 21.5, range -37.5-101.6), and SVA $59.5 \mathrm{~mm}$ (SD = 74.1, range -83.7-326.5).

Table 1: Demographics and Surgical Parameters.

\begin{tabular}{|c|c|c|c|}
\hline$N=349$ & Mean & Standard Deviation & Range \\
\hline Age, yrs & 57.4 & 15.5 & $(18.5,84.3)$ \\
\hline BMI & 27.2 & 5.7 & $(17,50.2)$ \\
\hline Levels Instrumented & 11.1 & 4.2 & $(1,19)$ \\
\hline Total OR Time, min & 392.0 & 123.4 & $(111,802)$ \\
\hline Total EBL, ml & 1930.3 & 1615.1 & $(50,12200)$ \\
\hline Total LOS & 7.4 & 4.1 & $(3,49)$ \\
\hline Preoperative Charlson Score & 1.6 & 1.7 & $(0,8)$ \\
\hline Preoperative Back Pain & 7.1 & 2.3 & $(0,10)$ \\
\hline Preoperative Leg Pain & 4.5 & 3.4 & $(0,10)$ \\
\hline Preoperative ODI & 42.0 & 18.9 & $(0,92)$ \\
\hline Preoperative Max Cobb & 42.2 & 20.8 & $(6.3,123.7)$ \\
\hline Preoperative SS & 31.5 & 12.3 & $(-6.1,69.2)$ \\
\hline Preoperative PT & 23.3 & 11.2 & $(-8.4,67.8)$ \\
\hline Preoperative PI & 54.8 & 12.9 & $(11.9,100.2)$ \\
\hline Preoperative PI-LL & 13.7 & 21.5 & $(-37.5,101.6)$ \\
\hline Preoperative LL & 41.0 & 21.6 & $(-30.7,88.9)$ \\
\hline Preoperative SVA, mm & 59.5 & 74.1 & $(-83.7,326.4)$ \\
\hline Postoperative Back Pain & 4.1 & 3.2 & $(0,10)$ \\
\hline Postoperative Leg Pain & 3.1 & 3.0 & $(0,10)$ \\
\hline Postoperative ODI & 27.3 & 20.6 & $(0,92)$ \\
\hline Postoperative Max Cobb & 22.5 & 15.5 & $(0.9,102.3)$ \\
\hline Postoperative SS & 32.3 & 11.1 & $(6.6,75.3)$ \\
\hline Postoperative PT & 22.0 & 10.7 & $(-6.3,58.5)$ \\
\hline Postoperative PI & 54.3 & 13.3 & $(14.6,92.2)$ \\
\hline
\end{tabular}




\begin{tabular}{|c|c|c|c|}
\hline Postoperative PI-LL & 4.5 & 16.3 & $(-29.3,72.4)$ \\
\hline Postoperative LL & 49.8 & 15.0 & $(-3.4,90.7)$ \\
\hline Postoperative SVA, mm & 33.0 & 55.3 & $(-97.7,237.1)$ \\
\hline$\Delta$ Back Pain & -2.9 & 3.3 & $(-10,5)$ \\
\hline$\Delta$ Leg Pain & -1.2 & 3.8 & $(-10,9)$ \\
\hline$\Delta$ ODI & -12.2 & 19.0 & $(-78,48)$ \\
\hline$\Delta$ Cobb & -23.1 & 15.8 & $(-65.4,5.5)$ \\
\hline$\Delta$ SS & 1.2 & 8.7 & $(-24.3,31.7)$ \\
\hline$\Delta$ PT & -1.0 & 8.7 & $(-28.8,21.5)$ \\
\hline$\Delta$ PI & 0.1 & 2.7 & $(-4.8,21.6)$ \\
\hline$\Delta$ PI-LL & -8.5 & 18.1 & $(-69.4,48)$ \\
\hline$\Delta$ LL & 8.7 & 17.9 & $(-45,71.1)$ \\
\hline$\Delta$ SVA, mm & -21.7 & 63.1 & $(-234.3,152.1)$ \\
\hline
\end{tabular}

Note: $\mathrm{BMI}=$ body mass index; $\mathrm{OR}=$ operating room; $\mathrm{EBL}=$ estimated blood loss; $\mathrm{LOS}=$ length of stay; ODI= ; $\mathrm{SS}=$; PT= ; PI= ; PI-LL= ; $\mathrm{LL}=; \mathrm{SVA}=; \Delta=$

Mean postoperative radiographic and outcome parameters: postoperative back pain VAS $4.1(\mathrm{SD}=3.2$, range $0-10)$, postoperative leg pain 3.1 ( $S D=3$, range $0-10$ ), postoperative ODI 27.3 ( $S D=20.6$, range 0-92), max cobb angle 22.5 degrees $(\mathrm{SD}=15.5$, range 0.9 102.3), PT 22.0 (SD = 10.7, range -6.3-58.5), PI 54.3 ( $\mathrm{SD}=13.3$, range 14.6-92.2), LL 49.8 (SD = 15.0, range 3.4-90.7), PI-LL 4.5 (SD = 16.3, range -29.3-72.4), and SVA $33.0 \mathrm{~mm}(\mathrm{SD}=55.3$, range -97.7 237.1). A univariate logistic regression tested significant association between operative (OR) time, as a continuous variable, and all complication categories (Table 2). Overall complications $(\mathrm{OR}=1.30$, $\mathrm{p}<0.001$ ), reoperation (OR 1.17, $\mathrm{p}=0.011$ ), major complications (OR = 1.16, $\mathrm{p}=0.014)$, minor complications (OR = 1.28, $\mathrm{p}<0.001)$, intra-op complications ( $\mathrm{OR}=1.37, \mathrm{p}<0.001$ ), before discharge complications ( $\mathrm{OR}=1.14, \mathrm{p}=0.028$ ), after discharge complications $(\mathrm{OR}=1.15, \mathrm{p}=0.009)$, cardiopulmonary complications $(\mathrm{OR}=1.21$, $\mathrm{p}=0.012$ ), infection (OR $=1.31, \mathrm{p}=0.005)$, operative complications $(\mathrm{OR}=1.34, \mathrm{p}<0.001)$, radiographic complications $(\mathrm{OR}=1.20, \mathrm{p}=$ $0.005)$, and wound complications ( $\mathrm{OR}=1.39, \mathrm{p}=0.025)$ were all found to be statistically significant.

Table 2: Univariate logistic regression using or time as a continuous variable

\begin{tabular}{|c|c|c|c|c|}
\hline Description & $\mathbf{N}(\%)$ & OR & 95\% CI \\
\hline Total N = 349 & & & & $(1.15,1.47)$ \\
\hline Complication & $237(67.9 \%)$ & 1.300 & $(1.04,1.32)$ & $<0.001$ \\
\hline Reoperation & $81(23.2 \%)$ & 1.170 & $(1.03,1.30)$ & 0.011 \\
\hline Major & $95(27.2 \%)$ & 1.155 & $(1.15,1.43)$ & $<.014$ \\
\hline Minor & $158(45.3 \%)$ & 1.281 & $(1.21,1.55)$ & $<0.001$ \\
\hline Intra op Complication & $93(26.6 \%)$ & 1.372 & $(1.01,1.28)$ & 0.001 \\
\hline $\begin{array}{c}\text { Before Discharge } \\
\text { Complication }\end{array}$ & $94(26.9 \%)$ & 1.138 & $(1.04,1.28)$ & 0.009 \\
\hline $\begin{array}{c}\text { After Discharge } \\
\text { Complication }\end{array}$ & $174(49.9 \%)$ & 1.152 & $(0.97,1.23)$ & 0.012 \\
\hline Cardiopulmonary & $48(13.8 \%)$ & 1.206 & $(1.09,1.57)$ & 0.152 \\
\hline Implant & $78(22.3 \%)$ & 1.093 & $(0.93,1.23)$ & 0.005 \\
\hline Infection & $27(7.7 \%)$ & 1.306 & $(1.19,1.52)$ & 0.335 \\
\hline Neurologic & $57(16.3 \%)$ & 1.069 & $(1.06,1.36)$ & $<0.001$ \\
\hline Operative & $101(28.9 \%)$ & 1.344 & $(0.58,3.28)$ & 0.005 \\
\hline Radiographic & $72(20.6 \%)$ & 1.200 & $(0.78,2.17)$ & 0.474 \\
\hline Renal & $1(0.3 \%)$ & 1.374 & $1.04,1.85)$ & 0.313 \\
\hline Vascular & $3(0.9 \%)$ & 1.388 & 0.025 \\
\hline Wound & $10(2.9 \%)$ & & \\
\hline
\end{tabular}

Note: Categories with statistically significant correlation were used as variables for the multivariate regression analysis. 
Multivariate logistic regressions were then run using the complication categories found to have statistical significance in the univariate analysis (Table 3). The final multivariate analysis controlled for Charlson score, total instrumented levels, and institution. Of those tested, only major complications and infection were not statistically significant. Additional analyses included creating binary variables of OR time by the hour $(<3$ vs $>3,<4$ vs $>4$, etc) up to 9 hours, as the variable of interest in further multivariate logistic regression models. For surgeries $<3$ hours, $\mathrm{N}$
= 15 compared to $\mathrm{N}=334$ for surgeries $>3$ hours. Before discharge complications were found to be significant ( $O R=8.35, p=0.49$ ). When comparing surgeries $<4$ hours to $>4$ hours, $\mathrm{N}=42$ and 307 respectively, minor complications, before discharge complications and cardiopulmonary complications were statistically significant ( $p=0.046, p=0.013$, and 0.013 respectively). At 5 hours, minor complications and cardiopulmonary complications were significant ( $p=0.013$ and 0.004 respectively).

Table 3: Multivariate regression analysis.

\begin{tabular}{|c|c|c|c|c|}
\hline & $\mathbf{N}(\mathbf{\%})$ & $\mathbf{0 R}$ & $\mathbf{9 5 \%} \mathbf{C I}$ & $(1.18,1.68)$ \\
\hline Complication & $237(67.9 \%)$ & 1.411 & $(1.04,1.44)$ & $<0.001$ \\
\hline Reoperation & $81(23.2 \%)$ & 1.230 & $(1.00,0.99)$ & 0.014 \\
\hline Major & $95(27.2 \%)$ & 1.170 & $(1.24,1.72)$ & 0.057 \\
\hline Minor & $158(45.3 \%)$ & 1.461 & $(1.13,1.59)$ & 0.001 \\
\hline Intra op Complication & $93(26.6 \%)$ & 1.341 & $(1.08,1.48)$ & 0.004 \\
\hline $\begin{array}{c}\text { Before Discharge } \\
\text { Complication }\end{array}$ & $94(26.9 \%)$ & 1.260 & $(1.25,1.89)$ & 0.019 \\
\hline $\begin{array}{c}\text { After Discharge } \\
\text { Complication }\end{array}$ & $174(49.9 \%)$ & 1.190 & $(0.99,1.63)$ & $<0.001$ \\
\hline Cardiopulmonary & $48(13.8 \%)$ & 1.539 & $(1.08,1.51)$ & 0.061 \\
\hline Infection & $27(7.7 \%)$ & 1.270 & $(1.01,1.42)$ & 0.014 \\
\hline Operative & $101(28.9 \%)$ & 1.275 & $(1.04,2.46)$ & 0.035 \\
\hline Radiographic & $72(20.6 \%)$ & 1.198 & 1.600 & 0.032 \\
\hline Wound & $10(2.9 \%)$ & & \\
\hline
\end{tabular}

At 6 hours, overall complications, major complications, minor complications, intraoperative complications, and cardiopulmonary complications were significant $(\mathrm{p}=0.031, \mathrm{p}=0.042, \mathrm{p}=0.012, \mathrm{p}=$ 0.045 , and $p=0.003$ respectively). At 7 hours a substantial increase was seen in the number of categories that were statistically significant (Table 4). When comparing surgeries $<7$ hours $(\mathrm{N}=213$ ) to surgeries $>7$ hours $(\mathrm{N}=136)$, overall complications, reoperation, major, minor, intraoperative, before discharge, after discharge, cardiopulmonary, operative, and radiographic complications were all statistically significant. When comparing surgeries $<8$ hours $(\mathrm{N}=274)$ to surgeries $>8$ hours $(\mathrm{N}=75)$, overall complications, reoperation, minor, intraoperative, cardiopulmonary, infection, operative, and wound complications were all statistically significant (Table 5). Forty surgeries had a duration of greater than 9 hours. When compared to surgeries lasting $<9$ hours $(\mathrm{N}=309)$, minor complications and intraoperative complications were statistically significant.

Table 4: Comparison of complications at the 7-hour time point

\begin{tabular}{|c|c|c|c|c|c|}
\hline Description & $<7 \mathrm{Hr}$ & $7 \leq \mathrm{Hr}$ & OR & $95 \% \mathrm{CI}$ & $\mathbf{p}$ \\
\hline & $\mathrm{N}=213$ & $N=136$ & & & \\
\hline Complication & $124(58.2 \%)$ & 113 (83.1\%) & 4.713 & $(2.41,9.23)$ & $<0.001$ \\
\hline Reoperation & $40(18.8 \%)$ & $41(30.1 \%)$ & 2.226 & $(1.18,4.19)$ & 0.013 \\
\hline Major & $49(23 \%)$ & $46(33.8 \%)$ & 1.870 & $(1.03,3.41)$ & 0.041 \\
\hline Minor & 77 (36.2\%) & $81(59.6 \%)$ & 3.248 & $(1.80,5.86)$ & $<0.001$ \\
\hline $\begin{array}{l}\text { Intraoperative } \\
\text { Complication }\end{array}$ & $38(17.8 \%)$ & $55(40.4 \%)$ & 2.714 & $(1.46,5.04)$ & 0.002 \\
\hline $\begin{array}{l}\text { Before Discharge } \\
\text { Complication }\end{array}$ & $51(23.9 \%)$ & 43 (31.6\%) & 1.842 & $(1.01,3.38)$ & 0.048 \\
\hline $\begin{array}{l}\text { After Discharge } \\
\text { Complication }\end{array}$ & $89(41.8 \%)$ & 85 (62.5\%) & 3.049 & $(1.72,5.40)$ & $<0.001$ \\
\hline Cardiopulmonary & $23(10.8 \%)$ & 25 (18.4\%) & 3.913 & $(1.75,8.77)$ & 0.001 \\
\hline Infection & $10(4.7 \%)$ & 17 (12.5\%) & 2.488 & $(0.93,6.67)$ & 0.07 \\
\hline
\end{tabular}




\begin{tabular}{|c|c|c|c|c|c|}
\hline Operative & $44(2.1 \%)$ & $57(41.9 \%)$ & 2.107 & $(1.14,3.89)$ & 0.017 \\
\hline Radiographic & $32(15 \%)$ & $40(29.4 \%)$ & 2.363 & $(1.23,4.52)$ & 0.01 \\
\hline Wound & $4(18.8 \%)$ & $6(4.4 \%)$ & 2.591 & $(0.54,12.54)$ & 0.237 \\
\hline
\end{tabular}

Table 5: Comparison of complications at the 8-hour time point.

\begin{tabular}{|c|c|c|c|c|c|}
\hline Description & $<\mathbf{~ H r}$ & $\mathbf{8} \leq \mathbf{H r}$ & $\mathbf{O R}$ & $\mathbf{9 5 \%} \mathbf{C I}$ & $\mathbf{p}$ \\
\hline & $\mathrm{N}=274$ & $\mathrm{~N}=75$ & 3.370 & $(1.53,7.43)$ & $(1.14,4.51)$ \\
\hline Complication & $173(63.1 \%)$ & $64(85.3 \%)$ & 2.269 & $(0.73,2.88)$ & 0.003 \\
\hline Reoperation & $56(20.4 \%)$ & $25(33.3 \%)$ & 1.452 & $(1.34,4.97)$ & 0.286 \\
\hline Major & $70(25.6 \%)$ & $25(33.3 \%)$ & 2.584 & $(1.73,6.72)$ & 0.004 \\
\hline Minor & $110(40.2 \%)$ & $48(64.0 \%)$ & 3.407 & $(0.91,3.56)$ & 0.001 \\
\hline $\begin{array}{c}\text { Intraoperative } \\
\text { Complication }\end{array}$ & $56(20.4 \%)$ & $37(49.3 \%)$ & 1.798 & $(0.97,3.37)$ & 0.093 \\
\hline $\begin{array}{c}\text { Before Discharge } \\
\text { Complication }\end{array}$ & $68(24.8 \%)$ & $26(34.7 \%)$ & 1.806 & $(1.90,10.91)$ & 0.064 \\
\hline $\begin{array}{c}\text { After Discharge } \\
\text { Complication }\end{array}$ & $128(46.7 \%)$ & $46(61.3 \%)$ & 4.556 & $(1.42,11.36)$ & 0.001 \\
\hline Cardiopulmonary & $30(11 \%)$ & $18(24.0 \%)$ & 4.021 & $(1.19,4.59)$ & 0.009 \\
\hline Infection & $14(5.1 \%)$ & $13(17.3 \%)$ & 2.336 & $(0.59,2.41)$ & 0.014 \\
\hline Operative & $65(23.7 \%)$ & $36(48.0 \%)$ & 1.188 & $(1.09,36.83)$ & 0.632 \\
\hline Radiographic & $52(19 \%)$ & $20(26.7 \%)$ & 5.346 & 0.039 \\
\hline Wound & $5(1.8 \%)$ & $5(6.7 \%)$ & & \\
\hline
\end{tabular}

\section{Discussion}

The potential benefits of surgical treatment for adult spinal deformity are well established and demonstrate improvements in pain, function and self-image $[6-8,17,18]$. Numerous studies have demonstrated high complication rates associated with this surgical treatment $[7,9]$. Previous studies have aimed at identifying patient and surgical factors that are associated with increased risk of complications. Daubs et al [12]reported that increasing age was a significant factor in predicting complications in ASD surgery. Multiple studies have evaluated numerous parameters such as estimated blood loss, comorbidities, preoperative deformity, and ASA grade as risk factors for complications [14-16,19]. Previous studies have evaluated OR time as a discrete variable and not as a continuous variable. Our study specifically evaluated OR time as a continuous variable to quantify the risk of complication based on the duration of surgery.

In our multi-center review of 360 ASD patients treated surgically, the overall major complication rate of $27.2 \%$ is within the range reported in previous studies [7,9,19-22]. When evaluating OR time as a risk factor, an important factor is OR time's association with surgical factors such as the number of levels or the need for osteotomies. For instance surgeries requiring 10 levels are likely to have longer duration than those requiring 5 levels. Similarly, three column osteotomies not only add surgical time, but also increase the morbidity of the case. We controlled for both the number of levels and for three column osteotomies in our multivariate analysis. In doing so, we demonstrated a significant relationship between $\mathrm{OR}$ time and overall complication rate, major complications, intraoperative complication, radiographic, and wound complications. These complication rates were seen to significantly increase at the length of surgery increased.

We used the OR time and created binary variables at 1 hour time increments to assess any critical time after which there was an increase in the complication rates. The time points of 7 and 8 hours appeared significant, as an increasing number of complications were identified compared to other time points. Analysis of surgeries greater than 7 hours revealed 7 complication categories that were significantly greater compared to surgeries lasting less than 7 hours, including overall complication rate (83.1\% vs $58.2 \%)$ and reoperation rate $(30.1 \%$ vs $18.8 \%)$. Similarly, the 8 hour time point revealed 9 complication categories that were significantly greater for cases lasting greater than 8 hours and again included overall complication rate $(85.3 \%$ vs $63.1 \%)$ and reoperation $(33.3 \%$ vs $20.4 \%$ ). At the 9hour time point no significant findings were identified; however, only 40 patients were available with surgeries lasting greater than 9 hours. Insufficient power at the extremes of OR times ( 3 and 9 hours) may account for the absence of significant correlations between OR time and complications.

The literature has been inconclusive in regard to the association between patient comorbidities and complications. Schwab et al. [19] reviewed 953 ASD patients and found no association between any of the patient factors and major complications. Similarly, Daubs [12] and others have not found a correlation between comorbidities and complications $[7,9,23,24]$. However, others including Oldridge [25] have shown that patient factors such as age and comorbidities have direct correlation with complications $[12,26]$. Other studies 
have shown correlation between surgical factors such as EBL, staging, and anterior-posterior combined approach [12,14-16]. Outside the spine literature, Duchman [27] identified that OR time greater than 120 minutes was associated with increased shortterm morbidity and mortality in total joint arthroplasty. In a study evaluating 104,632 vascular and general surgery cases, cases taking $>95 \%$ of the upper confidence standard time limit had increased rates of complications [28]. Infection rates have also been linked to increased OR time $[29,30]$. In our study we found a correlation between OR time and both major and minor complication rates, but did not find a correlation with infection.

Many patient factors cannot be changed, however, surgical factors such as OR time can potentially be modified. Identifying the duration of surgery as a modifiable risk factor in such manner can thus allow for implementation of strategies to reduce the duration, as is seen with dual attending surgeon performance of complex ASD surgeries or consideration of a staged surgical approach as reported by Anand et al. [31] and Ames et al. [32]. The primary limitation of this study is the retrospective design. We controlled for number of levels and three column osteotomies since these have direct impact on the length of surgery. The numbers of patients at the extremes of the duration of surgery were small limiting the power of the study to detect any potential associations at these time points. This may be particularly relevant for the cases with longer durations ( $>9$ hours) given the dramatic increase in significant associations between OR time and complications at the 7 and 8 hour time points.

\section{Conclusion}

This study identified OR time as an independent risk factor for complications in surgical management of ASD after controlling for number of levels fused and three column osteotomies. Surgeries greater than 6 hours have a substantial increase in the number of significant associations of various complications. Steps to reduce surgical time may have significant effect on reducing complication rates.

\section{References}

1. (2005) Statistics NCFH. Health, United States, 2005: with chartbook on trends in the health of Americans.

2. (2010) Fu KM, Smith JS, Sansur CA, Shaffrey CI. Standardized measures of health status and disability and the decision to pursue operative treatment in elderly patients with degenerative scoliosis. Neurosurgery 66(1): 42-47.

3. Aebi M (2010) Correction and stabilization of a double major adult idiopathic scoliosis from T5/L5. Eur Spine J 19(3): 510-512.

4. Aebi M (2005) The adult scoliosis. Eur Spine J 14(10): 925-948.

5. Aebi M (2012) Less invasive approach to degenerative lumbar deformity surgery. Eur Spine J 21(3): 571-572.

6. Glassman SD, Howard JM, Sweet A, Carreon LY (2010) Complications and concerns with osteobiologics for spine fusion in clinical practice. Spine (Phila Pa 1976) 35(17): 1621-1628.

7. Carreon LY, Puno RM, Dimar JR, Glassman SD, Johnson JR (2003) Perioperative complications of posterior lumbar decompression and arthrodesis in older adults. J Bone Joint Surg Am 85-A: 2089-2092.
8. Lamartina C, Petruzzi M (2011) Adult de novo lumbar scoliosis. Posterior instrumented fusion with Smith-Peterson osteotomy, decompression and management of postoperative infection. Eur Spine J 20(9): 15801581.

9. Benz RJ, Ibrahim ZG, Afshar P, Garfin SR (2001) Predicting complications in elderly patients undergoing lumbar decompression. Clin Orthop Relat Res 384: 116-121.

10. Swank S, Lonstein JE, Moe JH, Winter RB, Bradford DS (1981) Surgical treatment of adult scoliosis. A review of two hundred and twenty-two cases. J Bone Joint Surg Am 63(2): 268-287.

11. Smith JS, Lafage V, Shaffrey CI, Schwab F, Lafage R, et al. (2016) International Spine Study G. Outcomes of Operative and Nonoperative Treatment for Adult Spinal Deformity: A Prospective, Multicenter, Propensity-Matched Cohort Assessment With Minimum 2-Year Followup. Neurosurgery 78: 851-861.

12. Daubs MD, Lenke LG, Cheh G, Stobbs G, Bridwell KH (2007) Adult spinal deformity surgery: complications and outcomes in patients over age 60 . Spine (Phila Pa 1976) 32(20): 2238-2244.

13. Schwab FJ, Hawkinson N, Lafage V, Smith JS, Hart R, et al. (2012) International Spine Study G. Risk factors for major peri-operative complications in adult spinal deformity surgery: A multi-center review of 953 consecutive patients. Eur Spine J 21(12): 2603-2610.

14. Hu SS (2004) Blood loss in adult spinal surgery. Eur Spine J 13 (Suppl 1): S3-S5.

15. Cho KJ, Suk SI, Park SR, Kim JH, Kim SS, et al. (2007) Complications in posterior fusion and instrumentation for degenerative lumbar scoliosis. Spine (Phila Pa 1976) 32(20): 2232-2237.

16. Olsen MA, Nepple JJ, Riew KD, Lenke LG, Bridwell KH, et al. (2008) Risk factors for surgical site infection following orthopaedic spinal operations. J Bone Joint Surg Am 90(1): 62-69.

17. Smith JS, Shaffrey CI, Glassman SD, Berven SH, Schwab FJ, et al. (2011) Spinal Deformity Study G. Risk-benefit assessment of surgery for adult scoliosis: an analysis based on patient age. Spine (Phila Pa 1976) 36: 817-824.

18. Smith JS, Fu KM, Urban P, Shaffrey CI (2008) Neurological symptoms and deficits in adults with scoliosis who present to a surgical clinic: Incidence and association with the choice of operative versus nonoperative management. J Neurosurg Spine 9(4): 326-331.

19. Schwab F, Lafage V, Farcy JP, Bridwell K, Glassman S, et al. (2007) Surgical rates and operative outcome analysis in thoracolumbar and lumbar major adult scoliosis: application of the new adult deformity classification. Spine (Phila Pa 1976) 32(24): 2723-2730.

20. Baron EM, Albert TJ (2006) Medical complications of surgical treatment of adult spinal deformity and how to avoid them. Spine (Phila Pa 1976) 31(19): S106-S118.

21. Eck KR, Bridwell KH, Ungacta FF, Riew KD, Lapp MA, et al. (2001) Complications and results of long adult deformity fusions down to 14, 15, and the sacrum. Spine (Phila Pa 1976) 26(9): E182-192.

22. Lapp MA, Bridwell KH, Lenke LG, Daniel Riew K, Linville DA, et al. (2001) Long-term complications in adult spinal deformity patients having combined surgery a comparison of primary to revision patients. Spine (Phila Pa 1976) 26(8): 973-983.

23. Ragab AA, Fye MA, Bohlman HH (2003) Surgery of the lumbar spine for spinal stenosis in 118 patients 70 years of age or older. Spine (Phila Pa 1976) 28(4): 348-353.

24. Kim HJ, Iyer S, Zebala LP, Kelly MP, Sciubba D, et al. (2016) International Spine Study G. Perioperative Neurologic Complications in Adult Spinal Deformity Surgery: Incidence and Risk factors in 564 Patients. Spine (Phila Pa 1976). 
25. Oldridge NB, Yuan Z, Stoll JE, Rimm AR (1994) Lumbar spine surgery and mortality among Medicare beneficiaries, 1986. Am J Public Health 84(8): 1292-1298.

26. Raffo CS, Lauerman WC (2006) Predicting morbidity and mortality of lumbar spine arthrodesis in patients in their ninth decade. Spine (Phila Pa 1976) 31(1): 99-103.

27. Duchman KR, Pugely AJ, Martin CT, Gao Y, Bedard NA, et al. (2017) Operative Time Affects Short-Term Complications in Total Joint Arthroplasty. J Arthroplasty 32(4): 1285-1291.

28. Daley BJ, Cecil W, Clarke PC, Cofer JB, Guillamondegui OD (2015) How slow is too slow? Correlation of operative time to complications: an analysis from the Tennessee Surgical Quality Collaborative. J Am Coll Surg 220(4): 550-558.

29. Naranje S, Lendway L, Mehle S, Gioe TJ (2015) Does operative time affect infection rate in primary total knee arthroplasty? Clin Orthop Relat Res 473(1): 64-69.

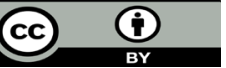

This work is licensed under Creative Commons Attribution 4.0 License

To Submit Your Article Click Here:

Submit Article

DOI: $10.32474 /$ OSMOAJ.2018.01.000124
30. Hosseini P, Mundis GM, Eastlack R, Nourian A, Pawelek J, et al. (2016) Do Longer Surgical Procedures Result in Greater Contamination of Surgeons' Hands? Clin Orthop Relat Res 474(47): 1707-1713.

31. Anand N, Cohen JE, Cohen RB, Khandehroo B, Kahwaty S, et al. (2017) Comparison of a Newer Versus Older Protocol for Circumferential Minimally Invasive Surgical (CMIS) Correction of Adult Spinal Deformity (ASD)-Evolution Over a 10-Year Experience. Spine Deform 5(3): 213223.

32. Ames CP, Barry JJ, Keshavarzi S, Dede O, Weber MH, et al. (2013) Perioperative Outcomes and Complications of Pedicle Subtraction Osteotomy in Cases With Single Versus Two Attending Surgeons. Spine Deform 1(1): 51-58

\section{Orthopedics and Sports Medicine} Open Access Journal

\section{OSMOAJ}

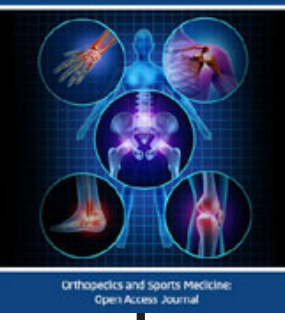

\section{Assets of Publishing with us}

- Global archiving of articles

- Immediate, unrestricted online access

- Rigorous Peer Review Process

- Authors Retain Copyrights

- Unique DOI for all articles 